Article

\title{
Approximating Forest Resource Dynamics in Peninsular Malaysia Using Parametric and Nonparametric Models, and Its Implications for Establishing Forest Reference (Emission) Levels under REDD+
}

\author{
Tetsuya Michinaka \\ Department of Forest Policy and Economics, Forestry and Forest Products Research Institute (FFPRI), \\ 1 Matsunosato, Tsukuba, Ibaraki 305-8687, Japan; michinaka.t@affrc.go.jp; Tel.: +81-29-829-8321; \\ Fax: +81-29-873-3799
}

Received: 1 May 2018; Accepted: 4 June 2018; Published: 5 June 2018

\begin{abstract}
Forest reference (emission) levels (FREL/FRLs) are baselines for REDD+, and 34 countries have submitted their FREL/FRLs to UNFCCC by January 2018. Most of them used simple historical average without considering the stages of forest transition. This research suggested that the period of calculating FREL/FRLs of simple historical average should be properly chosen if these countries are occupying multiple stages or sub-stages of forest transition. Moreover, as a case study, this research applied both parametric and nonparametric models to approximate forest area dynamics with regard to per capita GDP in Peninsular Malaysia from 1971 to 2016. This research found that, in the case of Peninsular Malaysia, among the parametric models, the biexponential model outperformed the other growth models, while two of the nonparametric models i.e. Friedman local averaging and Nadaraya-Watson kernel smoothing models are the best among all the models on the basis of their RSS, RMSE, and MAE indices. Based on the results of our leave-last-five-out CV, however, the research found that the biexponential and Nadaraya-Watson kernel smoothing models performed best, although the performance of the other two nonparametric models remains unknown. Nonparametric model results indicated that Peninsular Malaysia experienced four sub-stages since 1971 and each sub-stage had different linear trends, yet it still did not reach the turning point of forest transition. This research also found that a linear projection using historical deforestation data when the per capita GDP level reached US $\$ 8000$ was appropriate for setting FREL/FRLs.
\end{abstract}

Keywords: stages; forest transition; deforestation; REDD+; nonparametric model

\section{Introduction}

REDD+ (Reducing Emissions from Deforestation and forest Degradation plus the role of conservation, sustainable management of forests and enhancement of forest carbon stocks in developing countries) has become an important regime for mitigating global warming. By January 2018, 64 partner countries had joined the UN-REDD Program [1]; among them, after several years of efforts in Phase 1: Readiness Preparation Phase, 34 countries have submitted to the UNFCCC their forest reference (emission) levels (FREL/FRLs) as a baseline for measuring REDD+ results [2] for further technical assessment. However, most countries use a historical average as their FREL/FRLs, and few countries made linear projections of historical change, although they are in different stages of forest transition [3]. To assess REDD+ efforts effectively, FREL/FRLs by their national circumstances need to be properly calculated when a country is occupying multiple stages or sub-stages of forest transition. 
The forest transition hypothesis has been widely discussed as a uniform deforestation pattern [4-9]. Many developed countries have witnessed forest transitions from a net loss of forest areas to net forest area gain. Naturally, forest transitions are expected to occur in developing countries too. Originally, Mather [4] proposed the model of forest resource trends in four stages: 1. "unlimited" resources; 2. "depleting" resource; 3. "expanding" resource; and 4. equilibrium, while forest transition occurs between Stages 2 and 3. When forest transition hypothesis is expressed in a coordinate system, the $y$-axis usually represents forest cover, either by forest areas in hectares or by forest coverage rate in percentages, while the $x$-axis represents time or socioeconomic development levels, including per capita gross domestic product (GDP) and population density. Given the shape of the curve of forest resource trends, Nagata et al. [10,11] postulated a U-shape hypothesis of forest resources under which both forest areas and forest standing volume can be taken as a measure of forest resources; however, the latter was preferred because forest area may not reflect the real situation very well, even though sometimes forest area data may be easier to collect. Concerning the patterns of deforestation, another hypothesis, the environmental Kuznets curve (EKC), which is sourced from the Kuznets curve in economics and describes the relationships between inequality and economic development, is also widely discussed [12-17]. EKC, as the name implies, addresses environmental issues and sets environmental degradation or pollution as its $y$-axis and economic development as its $x$-axis in an inverted U-shaped curve. When applied to forest economics, the indicators for the $y$-axis could be deforestation or forest degradation. EKC explains forest degradation or deforestation from an economic development path. However, economic development in one country can help to reduce or stop the forest degradation and deforestation in that country but may cause forest degradation and deforestation in other countries because the increasing demand will make demanders purchase wood from international markets.

Forest resource dynamics vary by country. The same time point or level of socioeconomic development does not necessarily imply that the countries are at the same stage. Forest resource situations are a compound result of socioeconomic development and many other factors, such as political, cultural, and geographical situations. Internal or domestic motivation for environmental conservation and sustainable forest management is of key importance, followed by external or foreign motivations. Landslides and soil erosion may affect local residents the most, while floods can affect people in the whole watershed. When forests disappear at a large scale, the resultant climate change becomes a critical issue for the whole country, even to the rest of the world. However, livelihood maintenance is important for people. The forest transition or the bottom of the U-shaped curve is realized when economic development reaches a level where people have their own farmland or they can find a job where they do not have to clear forests and change forestland into other forms. When purchasing or obtaining forestland is expensive, private companies refrain from clearing forests for planting rubber and oil palm, or for expanding pastures for livestock production due to profitability. When forest products or ecological services become scarce, forests need to be increased. In the process of realizing forest transition in developing countries, foreign countries may take action, such as offering economic incentives, capacity building, and raising environmental consciousness. However, less developed countries may react unfavorably when developed countries preach about environment protection; after all, foreign demand for timber is responsible, to some extent, for the deforestation and forest degradation in less developed countries in the name of free trade and globalization.

By 1998, at least 146 deforestation studies had been conducted using an economic modeling approach [18]. In establishing REDD+ deforestation baseline, Huettner et al. [19] distinguished between two categories of approaches: retrospective and prospective, and evaluated their strengths and weaknesses. Herold et al. [20] and Gutman and Aguilar-Amuchastegui [21] identified three types of approaches to the establishment of a REDD+ reference level: the strictly historical approach, adjusted historical approach, and simulation models. Although forest transition theory proposes a simple model showing the pattern of forest cover changes over time, many other drivers have 
also been analyzed, including distance to roads and markets [22], fallow and cropping lengths [23], cultivated area [24], wood scarcity [25], land rent [7], historical deforestation, forest cover, per capita GDP, agricultural GDP, human population, road network [20], human development [26], and rural and urban populations [27], to name a few. Analysis methods have included simple regression, multiple regression, and non-linear regression at household, sub-national or national levels. However, it is a challenging task to identify a suitable generalized pattern suitable for all countries, with respect to either establishing forest reference (emission) levels (FREL/FRLs) or choosing drivers of deforestation.

Concerning the relationship between income level and deforestation, in a review of previous studies, Angelsen and Kaimowitz [28] commented that many studies are based on dubious FAO forest data, such that the driving forces of forest transition remain unclear. However, here we argue that, due to its availability, FAO data is still a valid choice. Michinaka and Miyamoto [26] used FAO and UNDP data in cluster and panel data analyses to evaluate forest area changes in relating to life expectancy at birth, adult literacy rate, per capita GDP, total human population, rural population rate, and agriculture GDP in 205 countries. These authors found several factors that negatively impact forest area in countries with low human development levels, but these impacts become positive in countries with higher human development levels. Despite the fact that other variables, such as government policy, wood scarcity, or the others listed above, can play important roles in forest transition [29], per capita GDP is widely applied as a proxy for a country's development status [9]. In most countries, forest cover has decreased when the demand for food and other commodities has increased in the course of its economic development and population growth [30]. The development status and wealth of a country may influence its land use policy [9]. In this research, we do not consider forest transition to be a passive function of time, but rather the result of efforts driven by national circumstances, for which, per capita GDP can be used as a proxy.

To understand forest resource dynamics in a country with its own diverse national socioeconomic circumstances, its detailed changes need to be examined to judge its stages of forest transition. Examining detailed trends can help to establish FREL/FRLs, which is important in the REDD+ regime. In this research, we first show the stages of forest transition curves by incorporating the contents of the main categories of forest and remind people of the changing deforestation levels and the importance of plantation forests. Second, we approximate the dynamics of forest sources in Peninsular Malaysia by applying four polynomial models, namely, linear, quadratic, cubic, and quartic models; and then power, biexponential, Gompertz growth, and the Michaelis-Menten models, as well as three nonparametric models, namely, Friedman local averaging, Nadaraya-Watson kernel smoothing, and Cleveland local regression models. Finally, we recommend a suitable period for calculating FREL/FRLs of simple historical averages by confirming their stages or sub-stages of forest transition for Peninsular Malaysia.

\section{Materials and Methods}

\subsection{Stages of Forest Transition Curves}

To implement REDD+, many graphs have been prepared by applying forest transition hypothesis [7,30-34]. Usually, four stages are shown. For the last stage, we consider that it can be divided into two stages: recovery stage and stabilization stage. Inoue [35] shows the forest utilization patterns into four stages: 1 . hunting and gathering age; 2 . agricultural age; 3 . industrial age; and 4. postindustrial age. Moreover, the changes of the components of forests are incorporated as plantation forest, secondary forest, and primary forest. Primary forest decreases but will stabilize after some point in time or economic development level. When adapting this idea to forest transition curve and considering the fact that the necessity of plantation forest has been realized and trees started to be planted in many countries much earlier, we modified the curve as shown in Figure 1. Between these stages, a period of transition may exist. Between stages 1 and 2, a period of accelerating deforestation may occur. Between stages 2 and 3, a period of decelerating deforestation may occur. Between stages 3 and 4 or at the beginning of stage 4 , a period of accelerating recovery may occur. Between Stages 
4 and 5, a period of decelerating recovery may occur. In the so-called "stabilization" stage, some minor ups and downs may occur. As pointed out by Mather [4] (p. 10), "The resource is bewildering in its extent and its complexity." Therefore, examining the detailed trends in a country may be helpful to set up a better baseline for REDD+.

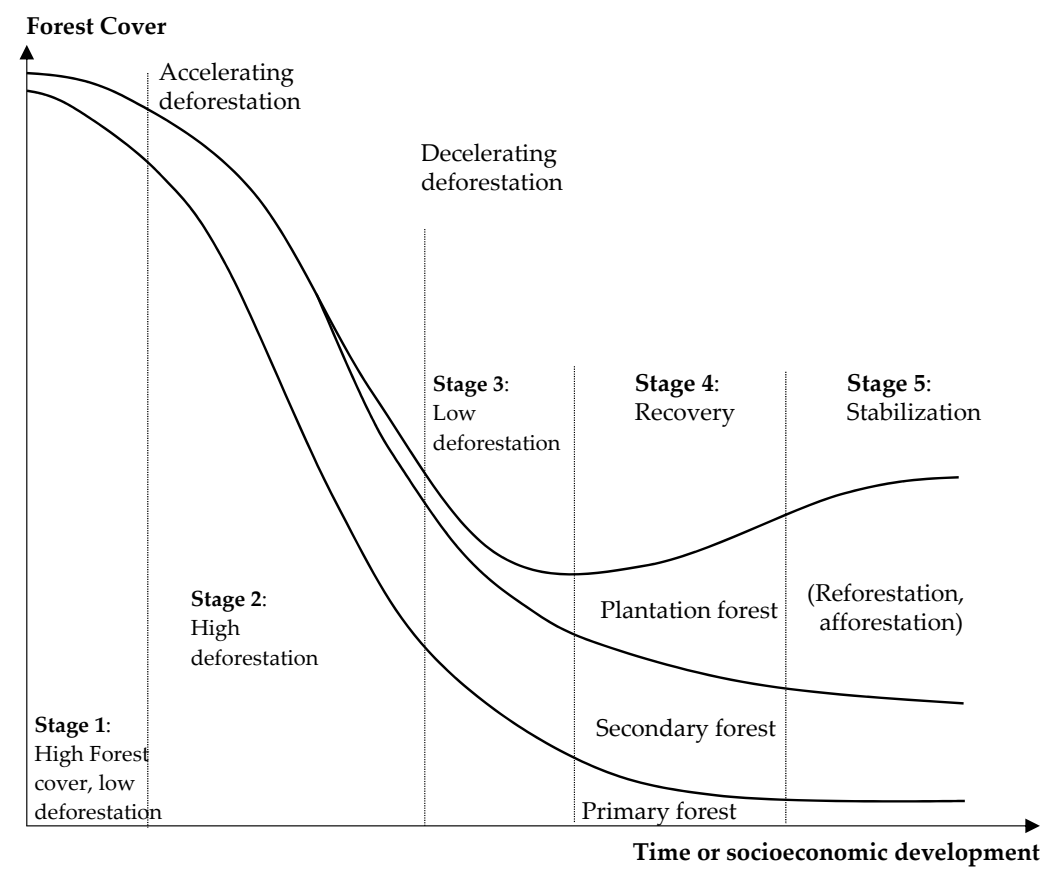

Figure 1. Stages of forest transition curves. Source: adapted from Inoue [35] and Angelsen [7].

\subsection{Study Site and Data}

In this research, we approximated the forest resource dynamics of Peninsular Malaysia. Malaysia, which is located in Southeast Asia, consists of Peninsular Malaysia and East Malaysia (Malaysian Borneo) (Figure 2). Peninsular Malaysia comprises of two federal territories and 11 states, while East Malaysia comprises of one federal territory and two states, Sarawak and Sabah. Given the different types of forest resource dynamics in the two regions, we analyzed only the forest area changes in Peninsular Malaysia. By the end of 2016, forested land accounted for 5.77 million ha or $43.8 \%$ of Peninsular Malaysia's total land area of 13.18 million ha, while in 1971, the forested area was as high as 7.88 million ha, representing $59.8 \%$ of land area [36]. Forest areas decreased more than $1 \%$ annually in the 1970s; however, since the early 1980s, deforestation slowed (Figure 3). In the early to mid-20th century, deforestation in Peninsular Malaysia occurred primarily due to the expansion of rubber, and from the 1960s onwards, the expansion of oil palm production became the main factor [37-39]. Newly planted fields of oil palm replaced forests, rubber land, and paddy fields.
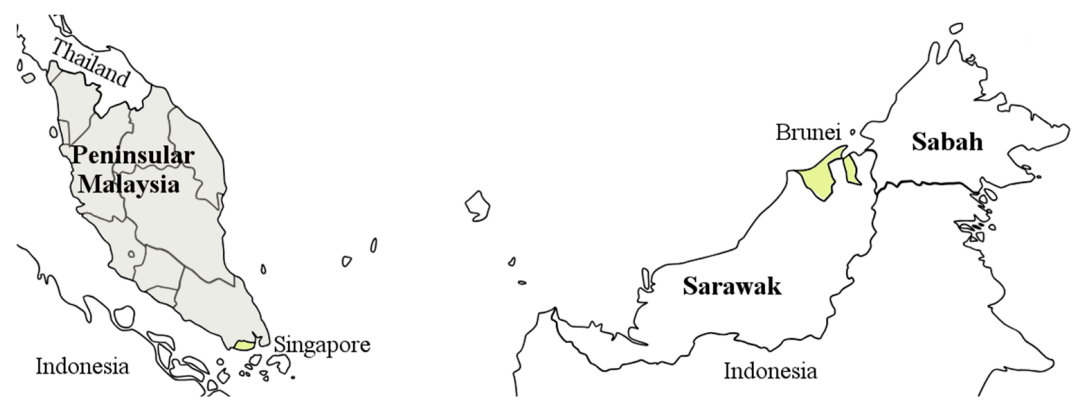

Figure 2. Study site: Peninsular Malaysia and its position relative to East Malaysia. 


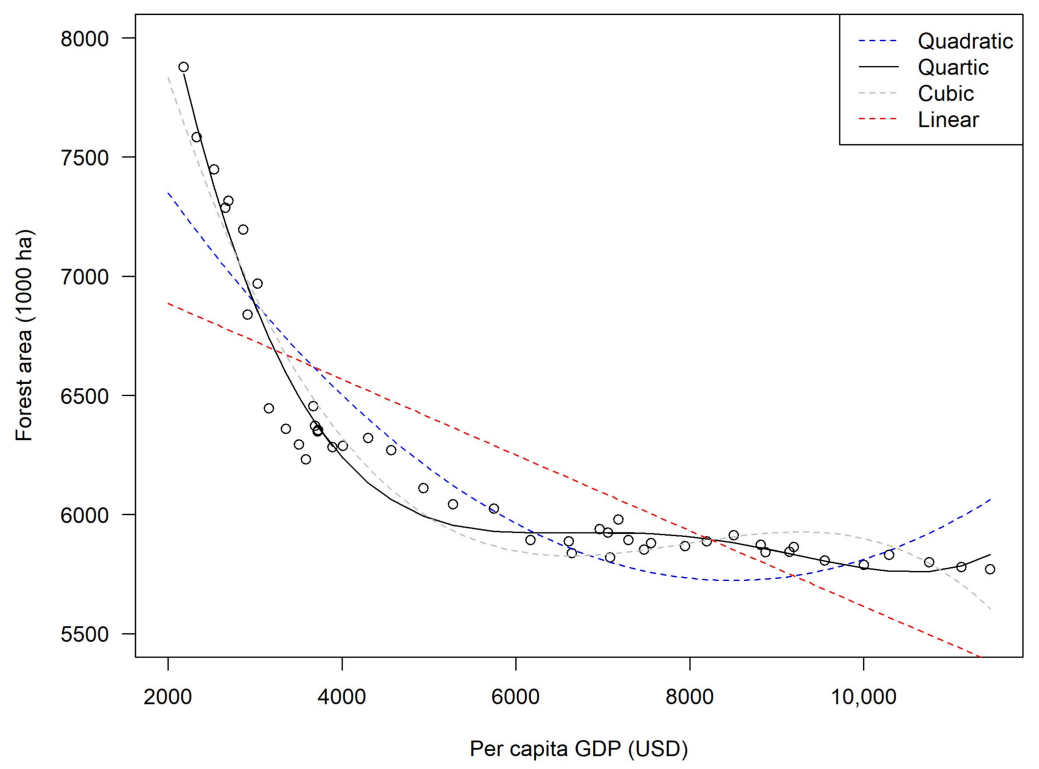

Figure 3. Land areas of forest, oil palm, and rubber plantations. Source: Forestry Department Peninsular Malaysia [36], Malaysian Palm Oil Board [40,41], Malaysian Rubber Board [40,41].

In the curve fitting, we took per capita GDP as an independent variable and forest area as an explained or dependent variable. The research period was set from 1971 to 2016. Annual GDP data at constant 1970, 1978, 1987, 2000, and 2010 prices were sourced from the Department of Statistics, Malaysia [42]. GDP data of Peninsular Malaysia were obtained by deducting the values of Sarawak and Sabah from the total GDP of Malaysia. GDP values in different years were adjusted using World Bank GDP deflators [43] to yield annual time series of constant 2010 prices for the analysis. Finally, these GDP values in Malaysian ringgit were converted to U.S. dollars by averaging the middle rates of 2010 [44] for the convenience of understanding. Population data were intercensal mid-year population estimates that were based on census data [38]. Thereafter, per capita GDP was calculated by combining GDP and population data. Forest area data are sourced from the Forestry Department, Peninsular Malaysia (FDPM). In Malaysia, forest was defined as land cover more than 0.5 ha, tree canopy no less than $10 \%$, trees higher than 5 meters, or trees able to reach these thresholds in situ [45], while rubber and oil palm plantations are not included in forested areas.

\subsection{Methods}

\subsubsection{Parametric Models}

The models used in this research were classified into two categories: parametric and nonparametric models. When fitting the trend for a short period in one stage, as shown in Figure 1, the linear model could be appropriate and sufficient. When fitting a longer period in one stage or in two or more stages, other models were expected to obtain better results. After checking the plot in Figure 3, we applied other parametric models aside from the linear model, namely, quadratic, cubic, quartic, power, biexponential, Gompertz growth, and Michaelis-Menten models. We cannot exhaust all the possible parametric models; rather, we chose some models arbitrarily. Among these, quadratic model has been widely used in fitting forest area changes because it can show a U-shaped locus [46], and cubic models were used in a few studies $[15,27,47,48]$. The Gompertz growth model was built by Benjamin Gompertz in 1825 [49] and has been widely used in fitting growth for biological and economic time series, such as trees and forest growth model [50-52]. The Michaelis-Menten model, which was originally used in kinetics in biochemistry, and the biexponential model, which is widely used in pharmacokinetics, can show a similar locus. Thus, we applied them in the curve fitting. We also applied 
other common parametric models, including quartic and power models. Equations for parametric regression models are shown in Table 1.

Table 1. Parametric models.

\begin{tabular}{ccc}
\hline No. & Models & Equations \\
\hline 1 & Linear & $y=a+b x$ \\
2 & Quadratic & $y=a+b x+c x^{2}$ \\
3 & Cubic & $y=a+b x+c x^{2}+d x^{3}$ \\
4 & Quartic & $y=a+b x+c x^{2}+d x^{3}+e x^{4}$ \\
5 & Power & $y=a x^{b}$ \\
6 & Michaelis-Menten & $y=\left(V_{\max } x\right) /\left(K_{m}+x\right)$ \\
7 & Biexponential & $y=A_{1} \exp \left(-e^{l r c 1} * x\right)+A_{2} \exp \left(-e^{l r c 2} * x\right)$ \\
8 & Gompertz growth & $y=a b^{x}+c$ \\
\hline
\end{tabular}

\subsubsection{Nonparametric Models}

Three nonparametric models were adopted in the research. For nonparametric models, Hollander et al. [53] emphasized "distribution-free property is a key aspect of many nonparametric procedures." Nonparametric methods can be utilized in situations where normal theory procedures cannot be utilized and are insensitive to outliers [53]. Nonparametric methods can detect structures that cannot be detected by traditional parametric methods [54]. The general nonparametric regression model can be given as follows:

$$
y_{i}=m\left(x_{i}\right)+e_{i}, \text { for } i=1, \ldots, n
$$

where the random variables $e_{i}$ are a random sample from a continuous population that has median 0 [53-55]. For a linear model or a nonlinear model, the function $m\left(\boldsymbol{x}_{i}\right)$ was specified in advance. However, for a nonparametric regression model, the function is not specified in advance. Fox and Weisberg [55] emphasized that "the object of nonparametric regression is to estimate the regression function $m\left(\boldsymbol{x}_{i}\right)$ directly, rather than to estimate parameters." In this research, three smoothing approaches introduced by Hollander et al. [53], namely, Friedman local averaging, Nadaraya-Watson kernel smoothing, and Cleveland local regression models, were applied.

R 3.4.4 [56] software was used in modeling. For nonlinear regression models other than polynomial models, getInitial, SSasymp, SSgompertz, SSbiexp, and SSmicmen functions were used to evaluate the initial parameter estimates, and nls function was used for model estimations. However, for the power model, estimations obtained by the logarithm function were used to evaluate initial parameter estimates. For nonparametric smoothing models, supsmu function was used for Friedman's local averaging models, loess function for Cleveland local regression models, and npregbw and npreg in $n p$ package [57] for Nadaraya-Watson kernel smoothing models.

\subsubsection{Model Comparations}

We evaluated the performance of the the parametric and nonparametric models after fitting. Akaike's information criterion (AIC), which is based on information theoretic consideration, is widely used in comparing and selecting models. In this research, AIC was calculated by

$$
\text { AIC }=(-2) \log (\text { maximum likelihood })+2 K=n+n \log (2 \pi)+n \log (\mathrm{RSS} / n)+2 \mathrm{~K}
$$

where RSS $=\sum\left(\text { actual value }{ }_{i}-\text { fitted value }_{i}\right)^{2}$ is the residual sum of squares, and $K$ is the total number of free parameters, including intercept and $\sigma^{2}$. When the sample size, $n$, is small, AIC may perform poorly. Therefore, a bias-corrected version of AIC, AICc was suggested [58-62]). AICc was defined as

$$
\mathrm{AICc}=\mathrm{AIC}+2 K(K+1) /(n-K-1) .
$$


Anderson et al. [63] and Burnham and Anderson [59] proposed a criterion for small sample size when the ratio $n / K<40$. The sample size of our data is 46 ; thus, we used AICc, rather than AIC, in comparing models. To rank the concerned models and ensure easy understanding, the differences in $\operatorname{AIC}\left(\Delta_{j}\right)$ were calculated as

$$
\Delta_{j}(\mathrm{AICc})=\mathrm{AICc}_{j}-\min \mathrm{AICc}
$$

where $\Delta_{j}(\mathrm{AICc})$ is the difference in AICc between $j$ th model and the best model $[59,64]$. Burnham and Anderson [59] proposed a rough rule of thumb by stating that models having $\Delta_{j}$ within 1-2 of the best model should receive consideration in making inferences. To make inferences concerning the relative strengths of evidence for each model, Akaike weights were also calculated as

$$
w_{j}=\exp \left(-\frac{1}{2} \Delta_{j}\right) / \sum_{r=1}^{R} \exp \left(-\frac{1}{2} \Delta_{r}\right), \text { and } \sum w_{j}=1
$$

where $w_{j}$ is the Akaike weights for $j$ th model $, r=1,2, \ldots, j, \ldots, R$. The sum of Akaike weights $\left(w_{j}\right)$ for $R$ models is 1 .

For nonparametric models, because calculating the number of free parameters and AICc is challenging, AICc was not calculated in this research. We calculated residual sum of squares (RSS), root mean squared error (RMSE), and mean absolute error (MAE) to measure their goodness of fit.

$$
\begin{aligned}
& \text { RMSE }=\text { square root }\left(\text { mean }\left(\left(\text { actual value }_{i}-\text { fitted value }_{i}\right)^{2}\right)\right), \\
& \mathrm{MAE}=\text { mean }\left(\text { absolute value }\left(\text { actual value }{ }_{i}-\text { fitted value }_{i}\right)\right)
\end{aligned}
$$

Besides AICc, RMSE, and MAE, cross-validation (CV) is also a widely-used method for comparing models. Because the data we used in this study are time series data and we emphasize the performance of models with respect to forecasting the near future, e.g., the next 5 years, we adopted a leave-last-five-out CV. First, we split the whole dataset into a training set (data from 1971 through 2011) and a test set (data from 2012 through 2016). Then, we used the training set for modelling while the test set, the actual values, for measuring forecasting accuracy based on the modelling results obtained in the previous step. Because forecasting by nonparametric regression remains challenging, we only calculated the results for the Nadaraya-Watson kernel smoothing model and made no CV calculations for the other two nonparametric models.

\section{Results}

\subsection{Parametric Models}

First, by setting forest areas in 1000 ha as a dependent variable and per capita GDP (in constant 2010 U.S. dollars) as an independent variable and using R software, we specified eight parametric regression models. Figure 4 shows the results of four polynomial functions, namely, linear, quadratic, cubic, and quartic functions.

We checked the general pattern of changes in forest areas based on per capita GDP and found that forest areas decreased sharply in intervals between a per capita GDP of approximately 2000 to approximately $\$ 5000$, as shown in Figure 4. Between $\$ 5000$ and $\$ 10,000$, forest areas fluctuated slightly; when per capita GDP exceeded $\$ 10,000$, forest areas decreased slightly. Figure 4 shows that the performance of the linear model is not sufficient to reveal the entire picture of changes in forest areas in relation to per capita GDP. Quadratic and cubic models outperformed the linear model. However, from the view of future projection, quadratic model produced a sharp increase, while the cubic model showed a sharp decrease at the end of the curve; both conditions are not ideal. The quartic model showed a considerably milder trend at the end and performed the best among four models. However, the end section of the quartic curve is not ideal because actual values exhibited a slight downward trend. 


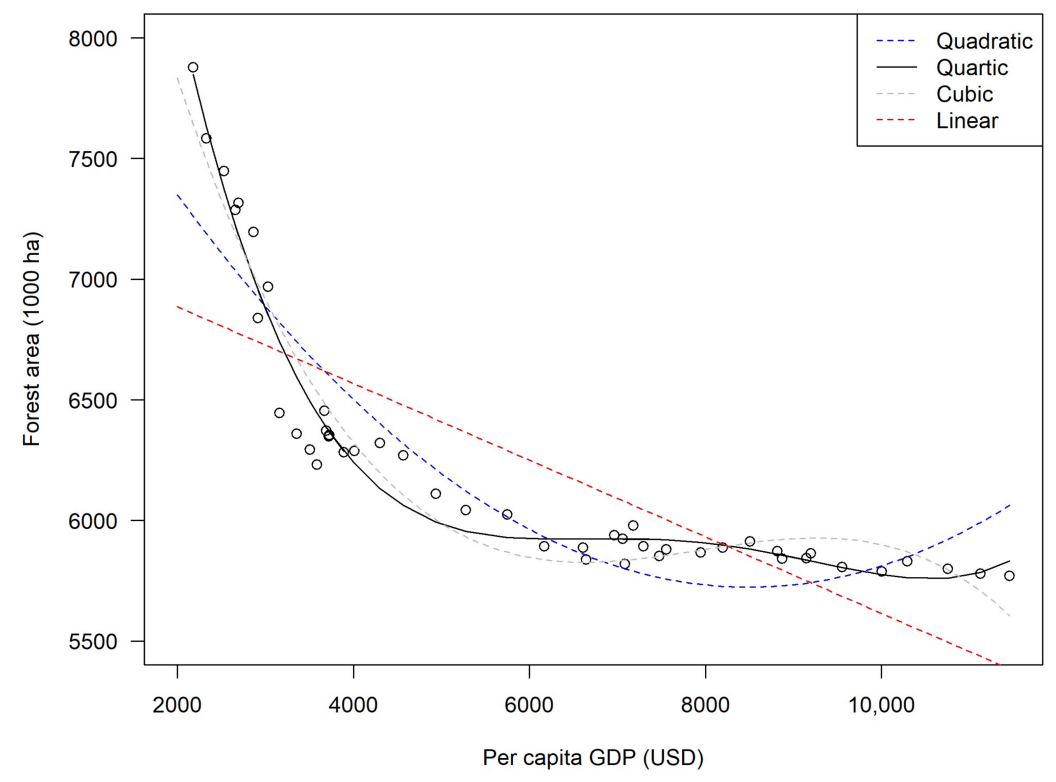

Figure 4. Results of curve fitting by linear, quadratic, cubic, and quartic functions.

By calculating the first-order derivatives of the quadratic function and setting it to 0 , we observed the bottom of the parabola when per capita GDP reached approximately $\$ 8000$, showing a decreasing trend before approximately $\$ 8000$ and an increasing trend after approximately $\$ 8000$. However, Figure 4 shows that deforestation slowed down considerably earlier than the point at approximately $\$ 8000$. By contrast, a cubic curve seems to reflect the changes more efficiently. By calculating the first-order derivative of the cubic function in Table 1, we obtained

$$
y^{\prime}(x)=b+2 c x+3 d x^{2} .
$$

The solutions for $y^{\prime}=0$, in Equation (7), were approximately $\$ 6500$ and approximately $\$ 9000$ of per capita GDP. This finding implied that the downward trend for the forest areas stopped and changed to an upward trend at approximately $\$ 6500$. However, approximately $\$ 9000$ was another turning point where the upward trend stopped. By checking Figure 4, we observed that the actual forest areas started a downward trend earlier than approximately $\$ 9000$. Next, we checked the quartic function. By calculating the first-order and second-order derivatives of the quartic function, we obtained

$$
y^{\prime}(x)=b+2 c x+3 d x^{2}+4 e x^{3}
$$

and

$$
y^{\prime \prime}(x)=2 c+6 d x+12 e x^{2} .
$$

First-order derivatives (Equation (8)) show the slopes of the tangent lines or the rates of change for the quartic function, while second-order derivatives (Equation (9)) show the changes in the slopes of the tangent lines for the quartic curve. By plotting the results of Equations (8) and (9), as shown in Figure 5, we found the slopes of the tangent lines were negative, and forest areas decreased sharply until approximately $\$ 6000$ of per capita GDP; after approximately $\$ 6000$, the slopes of the tangent lines were still negative, but they were decreasing in absolute value and approaching zero. When per capita GDP reached approximately $\$ 6600$, the slope of the tangent line became 0 . After $\$ 6600$, the slope of the tangent line began to decrease again, although slowly. This minor downward trend stopped at approximately $\$ 9000$ and changed to an upward trend. 


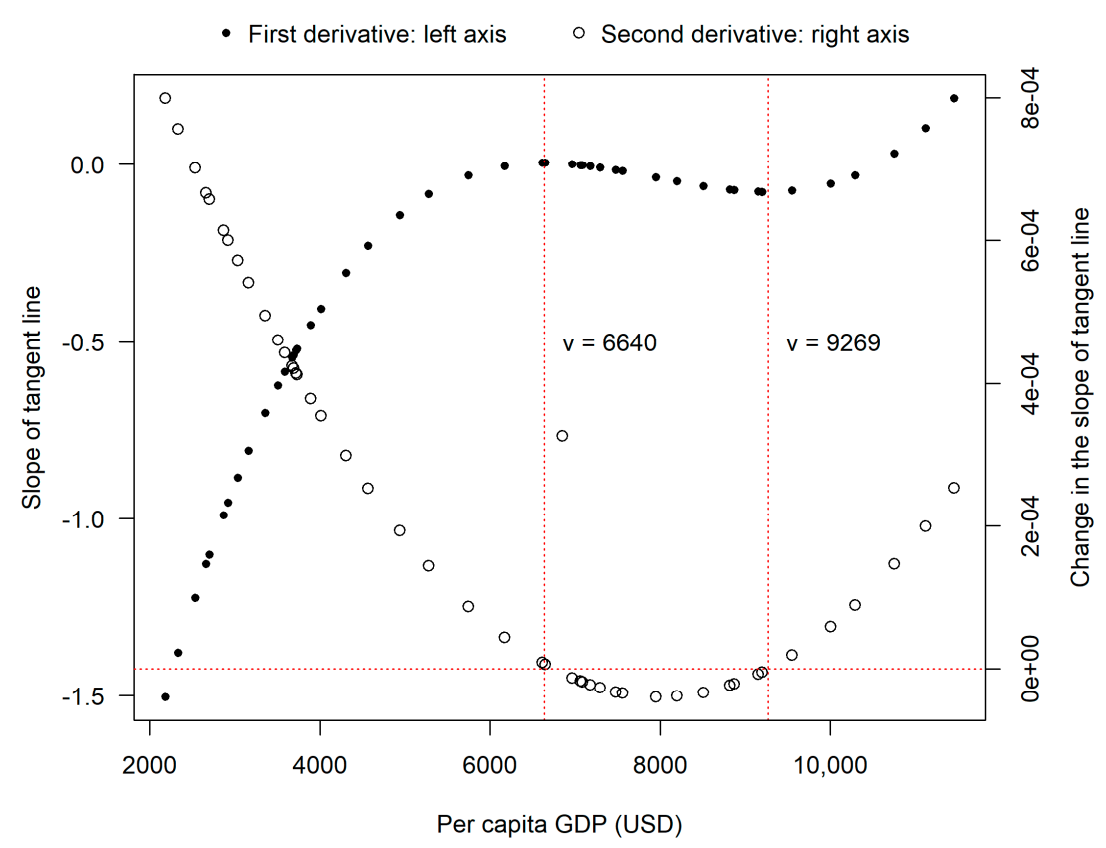

Figure 5. First- and second-order derivatives of quartic function.

Aside from polynomial models, four other parametric models were specified, as shown in Figure 6. First, in Figure 6, the fitted values by the power function are far from the actual values compared against the other three models. Second, the Michaelis-Menten model fitted better than the power model but did not perform well after approximately $\$ 8000$ compared with the Gompertz growth and biexponential models. The fittings between Gompertz growth and biexponential models before approximately $\$ 9000$ are difficult to distinguish. A visual check of the ends of the curves indicates that the biexponential model provides the best goodness of fit, showing a slight downward trend.

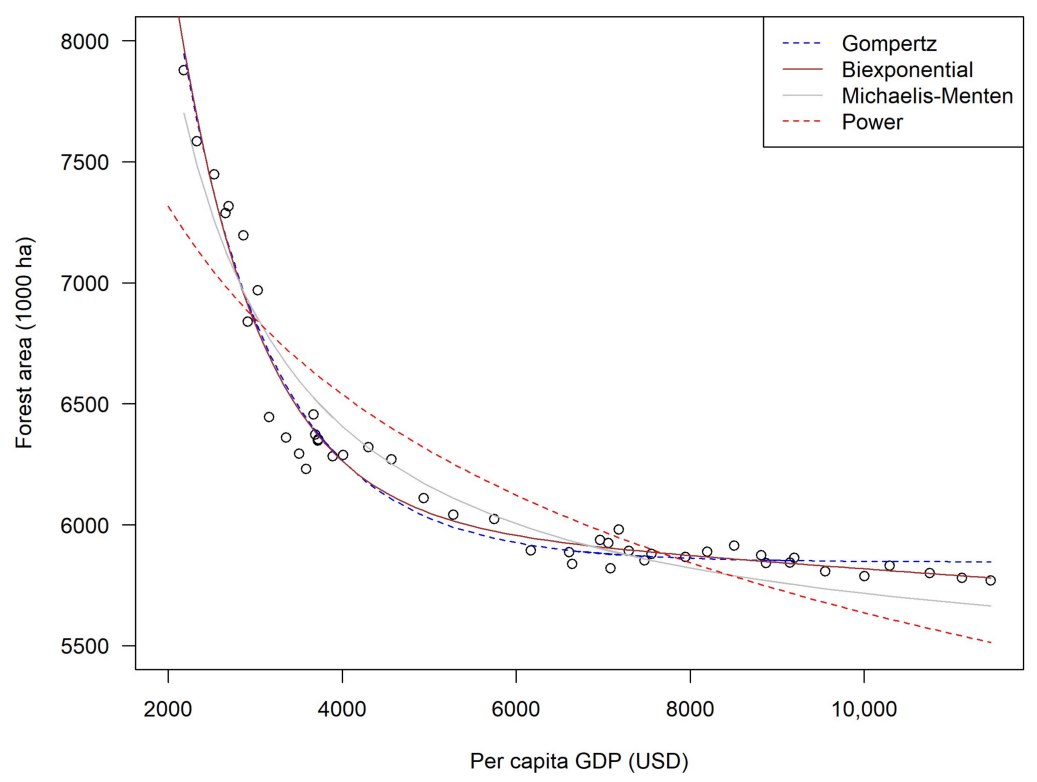

Figure 6. Curve fitting by other parametric models.

Table 2 shows the model selection statistics, including RSS, log (maximum likelihood), corrected AIC (AICc), $\triangle \mathrm{AICc}$, Akaike weights $w_{j}$, RMSE and MAE. First, eight models are ranked in the same order in their dimensions of RSS, log (L), AICc, RMSE, and MAE. The biexponential model is 
at the top with the lowest AICc. However, $\Delta_{2}$ (AICc) is 0.95 , which is less than 2, thereby showing that the second model, which is the Gompertz growth model, can be considered one of the best models. The quartic model ranked third and is less plausible compared with the best model by $\Delta_{3}$ (AICc) of 9.182. However, the quartic model outperformed five other parametric models. The linear model is the poorest among the eight models. Second, the results by Akaike weights, $w_{j}$, show that the weight of evidence or probability for the biexponential model, being the best model, was 0.612 ; that of the Gompertz growth model was 0.382; that of the quartic model was 0.006; and that of all the others was 0 . The evidence ratio was calculated by $w_{i} / w_{j}$, and we obtained $w_{1} / w_{2}=1.60, w_{1} / w_{3}=102$, $w_{2} / w_{3}=63.67$, thereby showing that the first model is not the best model. However, both the first and second models are much better than the third model. Given that $0.612+0.382=0.994$, the evidence shows that the best is among the first two models. For polynomial functions, the order is as follows: quartic $>$ cubic $>$ quadratic $>$ linear.

Table 2. Summary of model selection statistics.

\begin{tabular}{cccccccccc}
\hline No. & Models & RSS & Log $(\mathbf{L})$ & No. Par & AICc & $\boldsymbol{\Delta}_{\mathbf{j}}$ & $\boldsymbol{w}_{\mathbf{j}}$ & RMSE & MAE \\
\hline 1 & Biex. & 419,622 & -275.00 & 5 & 561.49 & 0.00 & 0.612 & 96 & 67 \\
2 & Gom. & 452,497 & -276.73 & 4 & 562.44 & 0.95 & 0.382 & 99 & 74 \\
3 & Quartic & 483,607 & -278.26 & 6 & 570.67 & 9.18 & 0.006 & 103 & 74 \\
4 & Cubic & 833,612 & -290.78 & 5 & 593.07 & 31.58 & 0.000 & 135 & 107 \\
5 & M-M & 902,040 & -292.60 & 3 & 591.77 & 30.28 & 0.000 & 140 & 114 \\
6 & Qua. & $2,246,443$ & -313.58 & 4 & 636.14 & 74.65 & 0.000 & 221 & 177 \\
7 & Power & $2,698,227$ & -317.80 & 3 & 642.17 & 80.68 & 0.000 & 242 & 201 \\
8 & Linear & $5,017,771$ & -332.07 & 3 & 670.70 & 109.21 & 0.000 & 330 & 271 \\
\hline
\end{tabular}

\subsection{Nonparametric Models}

The results of the nonparametric models are shown in Figure 7 and Table 3. First, for the interval of more than approximately $\$ 8000$ of per capita GDP, all three models almost overlapped and fitted well (Figure 7a). For the part of the curve in the interval of less than approximately $\$ 8000$, the Friedman and Nadaraya-Watson models outperformed the Cleveland model. The Cleveland local regression model seemed to have over-smoothed the curve. Second, by checking Figure $7 b, c$, we perceived that the fitted curve might be divided into four sub-stages. Sub-stage I ended at approximately somewhere before $\$ 4000$ of per capita GDP with a higher deforestation rate. This sub-stage may belong to Stage 2 of forest transition. Sub-stage II ended at approximately $\$ 7000$, with a lower deforestation rate than sub-stage I. This sub-stage may belong to the latter period of Stage 2 or earlier period of Stage 3 of forest transition. Sub-stage III ended at approximately $\$ 8000$, showing an approximately stable or horizontal trend. The last sub-stage, sub-stage IV started from approximately $\$ 8000$. In this sub-stage, slight deforestation occurred. Sub-stages III and IV may belong to Stage 3 of forest transition. Generally speaking, except for the third sub-stage, all other sub-stages show an approximately linear and decrease trend in forest areas; however, the deforestation level was becoming increasingly lower. Figure $7 \mathrm{~d}$ shows that the Cleveland model fitted the curve with two stages, both of which were approximately linear and may belong to the Stages 2 and 3 of forest transition, respectively.

Table 3 shows the RSS, RMSE, and MAE statistical performance indices. Among the three models, the Friedman model is the best, with the lowest RSS, RMSE, and MAE. AIC is not calculated because calculating the number of free parameters for nonparametric models is complicated. By comparing these results with the applied parametric models, we found that the nonparametric, Friedman local averaging, and Nadaraya-Watson kernel smoothing models were the best among all the models discussed in the research. The biexponential model and the Gompertz growth model-the two parametric models-ranked third and fourth, respectively, while the Cleveland local regression model—the third nonparametric model—ranked fifth. 


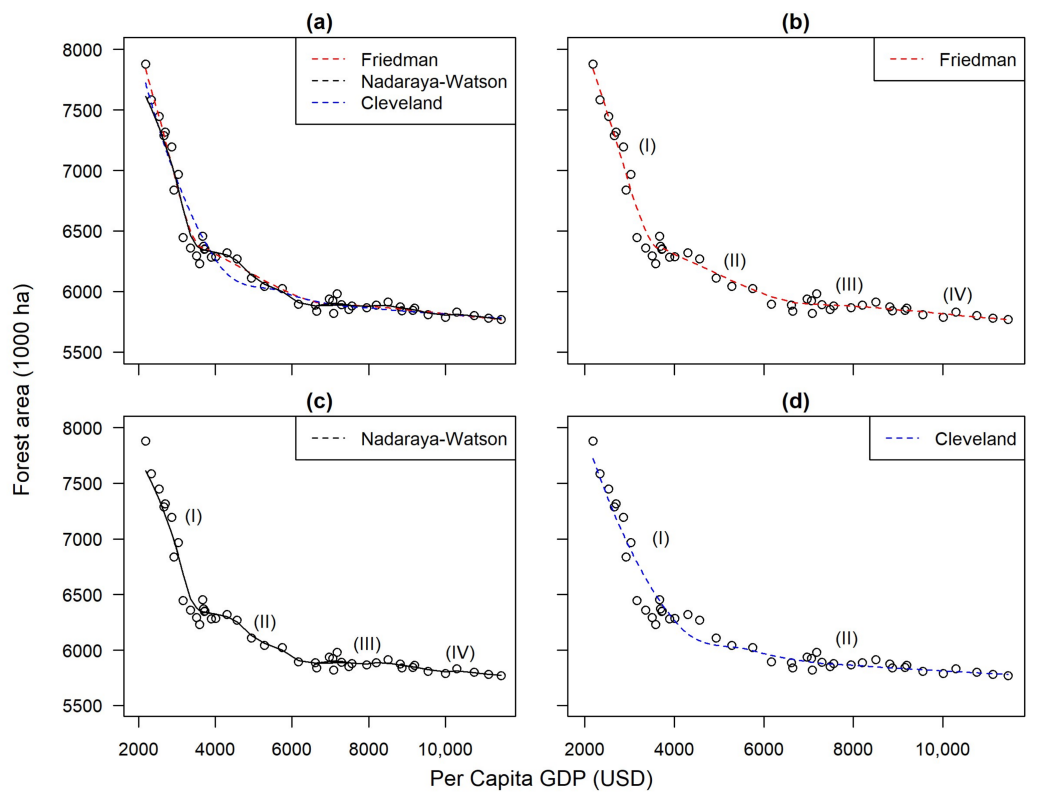

Figure 7. Curve fitting by nonparametric models.

Table 3. Results for nonparametric models.

\begin{tabular}{ccccc}
\hline No. & Models & RSS & RMSE & MAE \\
\hline 9 & Friedman & 200,926 & 66 & 46 \\
10 & Nadaraya-Watson & 285,149 & 79 & 52 \\
11 & Cleveland & 569,620 & 111 & 75 \\
\hline
\end{tabular}

\subsection{Cross-Validation}

Table 4 shows the results of our leave-last-five-out CV. We found the biexponential model, which is a parametric regression, and the Nadaraya-Watson kernel smoothing model, a nonparametric regression, to perform the best, followed by Gompertz growth and Michaelis-Menten models. Interestingly, the linear model outperformed the quadratic, cubic, and quartic models.

Table 4. Results of leave-last-five-out CV.

\begin{tabular}{cccc}
\hline No. & Models & RMSE & MAE \\
\hline 1 & Biexponential & 25 & 22 \\
2 & Nadaraya-Watson kernel smoothing & 25 & 23 \\
3 & Gompertz growth & 76 & 73 \\
4 & Michaelis-Menten & 132 & 131 \\
5 & Power & 322 & 320 \\
6 & linear & 533 & 525 \\
7 & Quadratic & 789 & 749 \\
8 & Cubic & 849 & 754 \\
9 & Quartic & 895 & 758 \\
\hline
\end{tabular}

\section{Discussion}

Two nonparametric models, namely, Friedman local averaging and Nadaraya-Watson kernel smoothing models, are the best among all the models discussed on the basis of their RSS, RMSE, and MAE indices. Based on the results of our leave-last-five-out CV, however, the biexponential and Nadaraya-Watson kernel smoothing models performed best, although the performance of the other two nonparametric models remain unknown. The graphs by the aforementioned two nonparametric 
models show that, with regard to per capita GDP, the whole period can be divided into four sub-stages. All the four sub-stages show an approximately linear trend. This finding shows that simple historical average of deforestation beyond $\$ 8000$ of per capita GDP is appropriate for FREL/FRLs under the REDD+ regime in Peninsular Malaysia, that is, a linear projection by using the data over $\$ 8000$ may be helpful.

As observed by Angelsen [65], when the rate of deforestation is changing, the historical deforestation may "systematically under or overestimate the rate of deforestation in a BAU scenario". The empirical approach of calculating historical average of last 10 or five years seems arbitrary. Peninsular Malaysia reached the level of $\$ 8000$ of per capita GDP at 2010 constant price at around 2005; therefore, for Peninsular Malaysia, this research suggests that, when calculating historical average, the data from 2005 may be appropriate. Choosing a proper length of years not only can save time and fund, but also can provide a better evidence for FREL/FRLs. By applying eight parametric models, we found that the biexponential and Gompertz growth models perform the best in approximating forest resource dynamics in Peninsular Malaysia on the basis of their AICc values. Based on the results of RSS, RMSE, MAE, and leave-last-five-out CV indices, however, the biexponential model outperforms the Gompertz growth model and becomes the best model among parametric models.

Nonparametric and biexponential models reflect the forest area dynamics with regard to per capita GDP in Peninsular Malaysia as an open and right-end downward L-shaped locus. By referring to the forest transition and U-shape hypotheses, we find Peninsular Malaysia to be at the stage before reaching the bottom, because no recovery (a net gain of forest cover) has been observed, although it is possible that recovery could occur in the near future. Interestingly, for sub-stage III, between approximately $\$ 7000$ and approximately $\$ 8000$, forest areas seem to have reached the turning point by showing a stable period, to be followed by a sub-stage of slight deforestation; this trend seems to continue. On the basis of Figure 1, Peninsular Malaysia seems to be positioned in Stage 3 of forest transition. However, the locus is not a loop; rather, it consists of four linear trends.

Forecasting by nonparametric models is still challenging, if not impossible. However, forecasting by using the biexponential model for Peninsular Malaysia is possible by examining the potential per capita GDP growths. For example, if we could reasonably assume the growth rates of per capita GDP in Peninsular Malaysia in the coming five years or assume them under several scenarios, then we can obtain predicted values by using the estimated biexponential model. By using standard errors, we can also calculate the forecast intervals. This research applied only eight parametric models and three nonparametric models. Thus, the results of curve fitting by other models can be improved.

The approach of simulation models to establishing REDD+ baselines requires higher data availability and consistency than historical approach. However, if data are available, this research shows that, not only polynomial models, but also other parametric models, namely, power, biexponential, Gompertz growth, and the Michaelis-Menten models, and some nonparametric models can be the alternatives for simulating models. In the case of Peninsular Malaysia, model simulations may not provide better results than historical deforestation approach because a linear trend was confirmed since $\$ 8000$ of per capita GDP. However, for a country where nonlinear dynamics were found as shown in Figure 1, the models adopted in this research may be useful to the curve fitting. Angelsen and Ainembabazi [66] recommended to adjust to higher levels than historical deforestation to HFLD (high forest cover, low deforestation) countries, while to adjust to lower levels than historical deforestation to LFHD (low forest cover, high deforestation) countries. Biexponential, the Gompertz growth, Michaelis-Menten, power, and the Nadaraya-Watson kernel smoothing models may be used to set up a reasonable adjustment.

Using parametric modeling and per capita GDP as an independent variable, we obtained statistically significant estimations at the $1 \%$ level for all the parameters. This may not be true for all of Malaysia, including the other two states, Sarawak and Sabah, or other countries. If this is true, however, time may be an alternative independent variable for the above parametric and nonparametric regressions. 
Forest resource dynamics is diverse; therefore, renewing FREL/FRLs is important to reflect the changes in national situations.

FDPM has published its forest area data for Peninsular Malaysia since the colonial days, and for the official statistical data, the definition of forest by FAO is being adopted [67]. In 2011, in order to access satellite images and for REDD+ baselines, the tree canopy of $30 \%$, rather than $10 \%$, was decided by the Ministry of Natural Resources Malaysia [67,68]; however, this criterion is not used for the official forest area data. Shukri [67] found that the forest cover loss by the FDPM statistical data is lower than those shown in geospatial data by World Resource Institute (WRI) and World Wildlife Fund (WWF). The author explains when some new areas are gazetted as Permanent Reserved Forest (PRF), they will be included as forest while they may not necessarily be forested areas currently. Besides, a clearcutting to plantation forest under sustainable management may also be seen as a forest cover loss by satellite imagery. When data are improved, better results can be expected by using the same approach.

\section{Conclusions}

Forest resource dynamics is diversified and nonparametric models are useful to approximate forest resource dynamics. Some parametric models, such as the biexponential and Gompertz growth models, may outperform the commonly used parametric models, such as linear, quadratic, cubic, and quartic models. The results by nonparametric or parametric models can provide evidence for judging the stages of forest transition and for choosing the period of calculating FREL/FRLs of simple historical average under REDD+. When historical data show that a country or region is occupying multiple different stages or sub-stages of forest transition, it is necessary to choose an appropriate period to establish the REDD+ baseline. A period with a linear trend is preferred for the strictly historical approach. However, if nonlinear dynamics were found, the simulation models can be useful to set up the level of adjustment to historical deforestation averages for the adjusted historical approach.

Using per capita GDP under proper scenarios, parametric models, such as the biexponential and Gompertz growth models, and some nonparametric models, such as the Nadaraya-Watson kernel smoothing model, can be used for forecasting the near future and set up the baselines for REDD+.

Funding: This research was conducted in "the project to support activities for promoting REDD+ by private companies and non-governmental organizations" using subsidy from Forestry Agency, Japan.

Acknowledgments: Thanks are due to Mohd Parid Mamat, Zakaria Noor Aini, Mukrimah Abdullah, Motoe Miyamoto, and related departments in Peninsular Malaysia for arranging the field trip and for their cooperation in data collection. Thanks are also due to Satoshi Tachibana and Nobuyuki Yamamoto for personal exchanges about the U-shape hypothesis of forest resources, which assisted in the completion of this paper. Finally, I thank the four anonymous reviewers for their insights to improve this paper.

Conflicts of Interest: The author declares no conflict of interest.

\section{References}

1. UN-REDD Programme. Available online: http://www.un-redd.org/ (accessed on 10 March 2018).

2. The UNFCCC REDD+ Web Platform. Available online: http:/ / redd.unfccc.int/ (accessed on 10 March 2018).

3. Neeff, T.; Maniatis, D.; Lee, D.; Mertens, E.; Jonckheere, I.; Perez, J.G.; DeValue, K.; Birigazzi, L.; Sandker, M.; Condor, R. From Reference Levels to Results Reporting: REDD+ under the UNFCCC; Forests and Climate Change Working Paper 15; Food and Agriculture Organization (FAO): Rome, Italy, 2017; p. 34.

4. Mather, A.S. Global Forest Resources; Belhaven Press, a Division of Printer Publishers: London, UK, 1990; p. 342, ISBN 1-85293-055-1.

5. Mather, A.S. The forest transition. Area 1992, 24, 367-379.

6. Mather, A.S.; Needle, C.L. The forest transition: A theoretical basis. Area 1998, 30, 117-124. [CrossRef]

7. Angelsen, A. Forest Cover Change in Space and Time: Combining the Von Thunen and Forest Transition Theories; World Bank Policy Research Working Paper No. 4117; World Bank Publications: Washington, DC, USA, 2007; p. 43.

8. Angelsen, A. (Ed.) Moving Ahead with REDD: Issues, Options and Implications; CIFOR: Bogor, Indonesia, 2008; p. 156. 
9. Kothke, M.; Leischaner, B.; Elsasser, P. Uniform global deforestation patterns-an empirical analysis. For. Policy Econ. 2013, 28, 23-37. [CrossRef]

10. Nagata, S.; Inoue, M.; Oka, Y. Testing u-shape hypothesis about forest resources. J. For. Econ. 1993, 123, 100-104. (In Japanese)

11. Nagata, S.; Inoue, M.; Oka, H. The Utility and Regeneration of Forest Resources; Rural Culture Association: Tokyo, Japan, 1994; p. 234. (In Japanese)

12. Shafik, N.; Bandyopadhyay, S. Economic Growth and Environmental Quality: Time Series and Cross-Country Evidence; Policy Research Working Paper Series 904; The World Bank: Washington, DC, USA, 1992; p. 55.

13. Panayotou, T. Empirical Tests and Policy Analysis of Environmental Degradation at Different Stages of Economic Development; Working Paper WP238, Technology and Employment Programme; International Labour Organization (ILO): Geneva, Switzerland, 1993; p. 42.

14. Stern, D.I.; Common, M.S.; Barbier, E.B. Economic growth and environmental degradation: The environmental Kuznets curve and sustainable development. World Dev. 1996, 24, 1151-1160. [CrossRef]

15. Bhattarai, M.; Hammig, M. Institutions and the environmental Kuznets curve for deforestation: A crosscountry analysis for Latin America, Africa and Asia. World Dev. 2001, 29, 995-1010. [CrossRef]

16. Stern, D.I. The rise and fall of the environmental Kuznets curve. World Dev. 2004, 32, 1419-1439. [CrossRef]

17. Choumert, J.; Motel, P.C.; Dakpo, H.K. Is the Environmental Kuznets Curve for deforestation a threatened theory? A meta-analysis of the literature. Ecol. Econ. 2013, 90, 19-28. [CrossRef]

18. Kaimowitz, D.; Angelsen, A. Economic Models of Tropical Deforestation: A Review; Center for International Forestry Research (CIFOR): Bogor, Indonesia, 1998; p. 153.

19. Huettner, M.; Leemans, R.; Kok, K.; Ebeling, J. A comparison of baseline methodologies for 'reducing emissions from deforestation and degradation'. Carbon Balance Manag. 2009, 4. [CrossRef] [PubMed]

20. Herold, M.; Angelsen, A.; Verchot, L.V.; Wijaya, A.; Ainembabazi, J.H. A stepwise framework for developing REDD+ reference levels. Chapter 16; In Analysing REDD+: Challenges and Choices; Angelsen, A., Brockhaus, M., Sunderlin, W.D., Verchot, L.V., Eds.; CIFOR: Bogor, Indonesia, 2012; pp. 279-299.

21. Gutman, P.; Aguilar-Amuchastegui, N. Reference Levels and Payments for REDD+: Lessons from the Recent Guyana-Norway Agreement. World Wildlife Fund USA, 2012. Available online: http:/ / assets.panda.org/ downloads/rls_and_payments_for_redd_lessons.pdf (accessed on 24 May 2012).

22. Southworth, F.; Dale, V.H.; O'Neill, R.V. Contrasting patterns of land use in Rondonia, Brazil: Simulating the effects on carbon release. Int. Soc. Sci. J. 1991, 130, 681-698.

23. Angelsen, A. Shifting Cultivation Expansion and the Intensity of Production: The Open Economy Case; Working Paper \#3. Chr.; Michelsen Institute: Bergen, Norway, 1994; p. 52.

24. Angelsen, A. Deforestation: Population or Market Driven? Different Approaches in Modeling of Agricultural Expansion; Working Paper \#9. Chr.; Michelsen Institute: Bergen, Norway, 1996; p. 42.

25. Hyde, W.F.; Amacher, G.S.; Magrath, W. Deforestation and forest land use: Theory, evidence and policy implications. World Bank Res. Obs. 1996, 11, 223-248. [CrossRef]

26. Michinaka, T.; Miyamoto, M. Forests and human development: Analysis pf the socio-economic factors affecting global forest area changes. J. For. Plan. 2013, 18, 141-150.

27. Ashraf, J.; Pandey, R.; Jong, W. Assessment of bio-physical, social and economic drivers for forest transition in Asia-Pacific region. For. Policy Econ. 2017, 76, 35-44. [CrossRef]

28. Angelsen, A.; Kaimowitz, D. Rethinking the causes of deforestation: Lessons from economic models. World Bank Res. Obs. 1999, 14, 73-98. [CrossRef] [PubMed]

29. Bae, J.S.; Joo, R.W.; Kim, Y. Forest transition in South Korea: Reality, path and drivers. Land Use Policy 2012, 29, 198-207. [CrossRef]

30. Barbier, E.B.; Delacote, P.; Wolfersberger, J. The economic analysis of the forest transition: A review. J. For. Econ. 2017, 27, 10-17. [CrossRef]

31. Angelsen, A.; Brockhaus, M.; Kanninen, M.; Sills, E.; Sunderlin, W.D.; Wertz-Kanounnikoff, S. (Eds.) Realising REDD+: National Strategy and Policy Options; CIFOR: Bogor, Indonesia, 2009; p. 361.

32. Oduro, K.A.; Mohren, G.M.J.; Pena-Claros, M.; Kyereh, B.; Arts, B. Tracing forest resource development in Ghana through forest transition pathways. Land Use Policy 2015, 48, 63-72. [CrossRef]

33. Perz, S.G. Grand Theory and Context-Specificity in the Study of Forest Dynamics: Forest Transition Theory and Other Directions. Prof. Geogr. 2007, 59, 105-114. [CrossRef] 
34. Barbier, E.B.; Burgess, J.C.; Grainger, A. The forest transition: Towards a more comprehensive theoretical framework. Land Use Policy 2010, 27, 98-107. [CrossRef]

35. Inoue, M. Basic forest conservation policy based on the distinctive feature of forest utilization patterns in the tropics. Rev. For. Culture 1992, 13, 27-32. (In Japanese)

36. Forestry Department Peninsular Malaysia (FDPM). (1979 and Other Years) Forestry Statistics Peninsular Malaysiay; FDPM: Kuala Lumpur, Malaysia, 1979.

37. Henson, I.E. An assessment of changes in biomass carbon stocks in tree crops and forests in Malaysia. J. Trop. For. Sci. 2005, 17, 279-296.

38. Abdullah, S.A.; Nakagoshi, N. Changes in agricultural landscape pattern and its spatial relationship with forestland in the State of Selangor, peninsular Malaysia. Landsc. Urban Plan. 2008, 87, 147-155. [CrossRef]

39. Miyamoto, M.; Parid, M.M.; Aini, Z.N.; Michinaka, T. Proximate and underlying causes of forest cover change in Peninsular Malaysia. For. Policy Econ. 2014, 44, 18-25. [CrossRef]

40. Ministry of Plantation Industries and Commodities (MPIC). (Various years) Statistics on Commodities; MPIC: Putrajaya, Malaysia, 2014.

41. Malaysian Administrative Modernisation and Management Planning Unit (MAMPU). Malaysia's Open Data Portal; Data and Information Are Subject to the Malaysian Government Open Data Terms of Use 1.0. Available online: www.data.gov.my (accessed on 12 April 2018).

42. Department of Statistics Malaysia. Table Publication GDP 2010-2016. p. 32. Available online: https:/ / www.dosm.gov.my/v1/uploads/files/1_Articles_By_Themes/National\%20Accounts / GDPbyState/Table\%20Publication\%20GDP\%202010-2016.pdf (accessed on 5 December 2017).

43. World Bank. World Development Indicators. Available online: https://data.worldbank.org/indicator/NY. GDP.DEFL.ZS?locations=MY (accessed on 30 October 2017).

44. Bank Negara Malaysia (Central Bank of Malaysia). Exchange Rates. Available online: http:/ / www.bnm.gov.my /index.php?ch=statistic\&pg=stats_exchangerates\&lang=en\&StartMth=1\& StartYr=2010\&EndMth=12\&EndYr=2010\&sess_time=1200\&pricetype=Mid\&unit=rm (accessed on 24 November 2017).

45. FAO (Forestry Department, Food and Agriculture Organization of the United Nations). Global Forest Resources Assessment 2010, Country Report, Malaysia. Rome, Italy, 2010. Available online: http:/ / www.fao. org/docrep/013/al558E/al558e.pdf (accessed on 10 May 2018).

46. Culas, R.J. REDD and Forest Transition: Tunnelling through the environmental Kuxnet curve. Ecol. Econ. 2012, 79, 44-51. [CrossRef]

47. Shafik, N. Economic development and environmental quality: An econometric analysis. Oxf. Econ. Pap. 1994, 46, 757-773. [CrossRef]

48. Michinaka, T.; Sokh, H.; Parid, M.M.; Abdullah, M.B.; Miyamoto, M. U-shape hypothesis of forest resources: In cases of Peninsular Malaysia and Cambodia. In Proceedings of the Abstracts of the 126th Annual Meeting of the Japanese Forest Society, Sapporo, Hokkaido, 27-29 March 2015; p. 97.

49. Winsor, C.P. The Gompertz curve as a growth curve. Proc. Natl. Acad. Sci. USA 1932, 18, 1-8. [CrossRef] [PubMed]

50. Sweda, T.; Koide, T. Applicability of Growth Equations to the Growth of Trees in Stem Radius (I). J. Jpn. For. Soc. 1981, 63, 113-124.

51. Minowa, M. A theoretical approach to forest growth modeling (I): The log-Mitscherlich theory. J. Jpn. For. Soc. 1982, 64, 461-467.

52. Yoshimoto, A.; Kamo, K.; Yanagihara, H. Environmental Data Analysis by R; Asakura Syoten: Tokyo, Japan, 2012; p. 202. (In Japanese)

53. Hollander, M.; Wolfe, D.A.; Chicken, E. Nonparametric Statistical Methods, 3rd ed.; Wiley: Hoboken, NJ, USA, 2014; p. 819, ISBN 978-0-470-38737-5.

54. Racine, J.; Li, Q. Nonparametric estimation of regression functions with both categorical and continuous data. J. Econom. 2004, 119, 99-130. [CrossRef]

55. Fox, J.; Weisberg, S. Nonparametric Regression in R: An Appendix to An R Companion to Applied Regression, 2nd ed.; SAGE Publications: Thousand Oaks, CA, USA, 2010; p. 17.

56. R Core Team. R: A Language and Environment for Statistical Computing; R Foundation for Statistical Computing: Vienna, Austria, 2018; Available online: https:/ / www.R-project.org/ (accessed on 30 March 2018). 
57. Racine, J.S.; Hayfield, T. Nonparametric Kernel Smoothing Methods for Mixed Data Types. R Package, np. p. 218. Available online: https:/ / cran.r-project.org/web/packages/np/np.pdf (accessed on 17 November 2017).

58. Sakamoto, Y.; Ishiguro, M.; Kitagawa, G. Akaike Information Criterion Statistics; Kyoritsu Shuppan: Tokyo, Japan, 1983; p. 254. (In Japanese)

59. Burnham, K.P.; Anderson, D.R. Model Selection and Multimodel Inference: A Practical Information-Theoretic Approach, 2nd ed.; Springer: New York, NY, USA, 2002; p. 488.

60. Sugiura, N. Further analysis of the data by Akaike's information criterion and the finite corrections. Commun. Stat.-Theory Methods 1978, 7, 13-26. [CrossRef]

61. Hurvich, C.M.; Tsai, C.L. Regression and time series model selection in small samples. Biometrika 1989, 76, 297-307. [CrossRef]

62. Hurvich, C.M.; Tsai, C.L. Model selection for extended quasi-likelihood models in small samples. Biometrics 1995, 51, 1077-1084. [CrossRef] [PubMed]

63. Anderson, D.R.; Link, W.A.; Johnson, D.H.; Burnham, K.P. Suggestions for Presenting the Results of Data Analysis. J. Wildl. Manag. 2001, 65, 373-378. [CrossRef]

64. Wagenmakers, E.J.; Farrell, S. AIC model selection using Akaike weights. Psychon. Bull. Rev. 2004, 11, 192-196. [CrossRef] [PubMed]

65. Angelsen, A. How do we set the reference levels for REDD payments. In Moving Ahead with REDD: Issues, Options and Implications; Angelsen, A., Ed.; CIFOR: Bogor, Indonesia, 2008; p. 156.

66. Angelsen, A.; Ainembabazi, J.H. Using the forest transition to predict deforestation and set reference levels for REDD+. In Proceedings of the 5th World Congress of Environmental and Resource Economists, Istanbul, Turkey, 28 June-2 July 2014.

67. Shukri, W.A.H.W.A.R. Comparison results of forest cover mapping of Peninsular Malaysia using geospatial technology. IOP Conf. Ser. Earth Environ. Sci. 2016, 37, 012027. [CrossRef]

68. Shukri, W.A.H.W.A.R.; Shahrulnizam, K.; Basri, M.M. Forest Cover Mapping using Geospatial Technology in Peninsular Malaysia-Towards the Enhancement of Future Spatial-based Forestry Reporting. In Proceedings of the 17th Malaysian Forestry Conference: A Century of Forest Management: Lessons Learnt \& the Way Forward, Sabah, Malaysia, 11-12 November 2014; pp. 96-115.

(C) 2018 by the author. Licensee MDPI, Basel, Switzerland. This article is an open access article distributed under the terms and conditions of the Creative Commons Attribution (CC BY) license (http:/ / creativecommons.org/licenses/by/4.0/). 